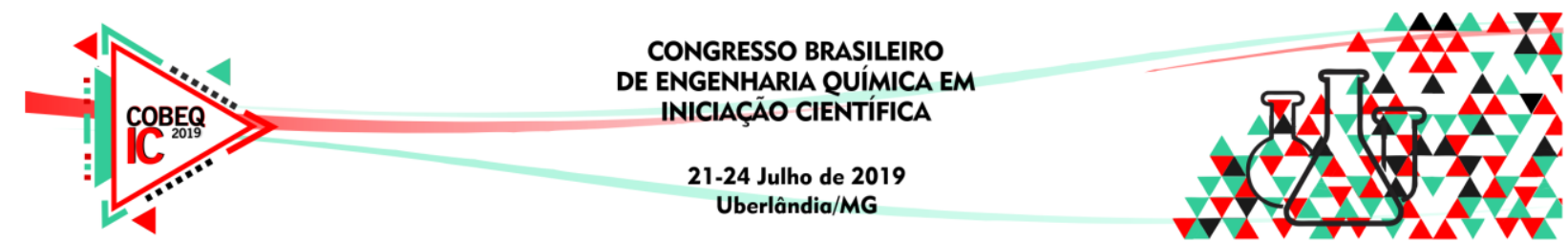

\title{
ESTUDO DA CINÉTICA DE SECAGEM DA CASCA DO MARACUJÁ (PASSIFLORA EDULIS FLAVICARPA)
}

\author{
C. M. P. FREITAS, G. S. RODRIGUES, D. J. SILVA e R. C. S. SOUSA \\ Universidade Federal de Viçosa, Departamento de Química \\ E-mail para contato: carinypolesca@gmail.com
}

\begin{abstract}
RESUMO - A atividade industrial de beneficiamento de polpas de frutas vem crescendo atualmente e com isso, possui destaque na geração de subprodutos, constituídos basicamente de cascas e sementes. Muitos destes subprodutos apresentam potencial para aproveitamento, no entanto ainda são pouco aproveitados e o seu descarte pode conduzir a impactos ambientais. Uma das alternativas de aproveitamento se dá por meio da secagem. Diante disso, estudouse a viabilidade da secagem das cascas do maracujá por meio da avaliação do comportamento do produto durante a secagem em uma estufa com circulação de ar a $55{ }^{\circ} \mathrm{C}$. O objetivo foi avaliar o comportamento desta etapa. De acordo com os resultados obtidos, pode-se afirmar que a partir de cinco horas a umidade em base seca não apresenta variações significativas.
\end{abstract}

\section{INTRODUÇÃO}

O aumento no consumo de derivados de frutas, como por exemplo polpas e sucos, pode ser explicado por questões de praticidade e busca por qualidade de vida com produtos saudáveis. No entanto, o processamento das frutas na indústria acarreta a geração de subprodutos, constituídos basicamente de cascas e sementes, que na maioria das vezes não possuem uma destinação adequada.

O maracujá é uma dessas frutas, muito citado porque a casca, um dos subprodutos do seu processamento, representa em média 53\% do peso total do fruto (OLIVEIRA et al., 2002). Este subproduto tem sido pesquisado e se mostra viável como fonte alimentar de bom valor nutricional (COELHO et al., 2011). A casca do maracujá é rica em aminoácidos, proteínas e carboidratos, além de contar com 10\% - 20\% de pectina (MANICA, 1981).

A indústria de alimentos possui como objetivo o aproveitamento dos subprodutos, a fim de minimizar os impactos ambientais e melhorar os benefícios financeiros. Uma das alternativas que pode ser implementada para tal finalidade é a secagem, visando a produção de farinha e agregação de valor ao subproduto (AKPINAR, 2006). A secagem é uma operação unitária com o objetivo de remover a água de um determinado material na forma de vapor (FERRUA \& BARCELOS, 2003).

O presente trabalho teve como objetivo elaborar a curva de secagem da casca do maracujá e estimar a cinética de secagem, dados essenciais para o projeto de unidades industriais. 


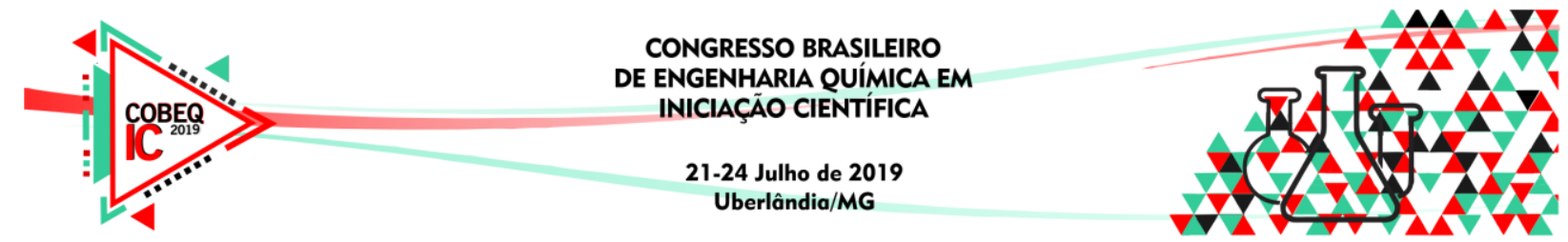

\section{MATERIAL E MÉTODOS}

\subsection{Material}

O material utilizado no estudo foi a casca do maracujá amarelo (Passiflora edulis $f$. flavicarpa). Os maracujás foram adquiridos em um comércio local na cidade de Viçosa-MG e selecionados de acordo com o grau de maturação, de forma que os frutos estivessem maduros. Os maracujás foram levados para o Laboratório de Processos Biotecnológicos na Universidade Federal de Viçosa. Os frutos foram lavados e cortados ao meio. A casca do maracujá foi cortada em pequenos pedaços $(1.0 \mathrm{~cm}$ de diâmetro).

\subsection{Métodos}

\subsubsection{Secagem da casca do maracujá}

A casca do maracujá foi submetida à secagem, em uma estufa marca NOVA ÉTICA, com circulação de ar e precisão de $\pm 3^{\circ} \mathrm{C}$. Os ensaios de secagem foram realizados em triplicata em temperatura equivalente a $55^{\circ} \mathrm{C}$.

O material foi distribuído, de tal forma que em todas as secagens houvesse a mesma massa e as mesmas proporções para os diferentes graus de maturação. Além disso, o material foi distribuído de maneira que formasse uma camada delgada, permitindo que a secagem ocorresse o mais uniformemente possível e preferencialmente por uma única superfície.

As pesagens foram feitas em intervalos de uma hora com o auxílio de balança analítica modelo FA2204C.

A umidade da amostra $\left(\mathrm{X}_{\mathrm{BS}}\right)$ durante a secagem, foi determinada pela Equação 1:

$$
X_{B S}=\left(\frac{m_{A}-m_{S S}}{m_{S S}}\right) 100
$$

Em que:

$\mathrm{m}_{\mathrm{A}}=$ massa da amostra no instante $\mathrm{t}$;

mss = massa do sólido seco.

\subsubsection{Estudo da cinética da secagem}

A curva da taxa de secagem foi construída com o objetivo de avaliar o comportamento da secagem. A área utilizada para cálculo foi a área do material utilizado para inserir a amostra, $63.617 \mathrm{~m}^{2}$.

Para construção da curva de taxa de secagem versus tempo, calculou-se a derivada $(\mathrm{dX} / \mathrm{dt})$ a partir da Equação 2, ajustada aos dados experimentais ( $\mathrm{X}_{\mathrm{BS}}$ versus $\left.\mathrm{t}\right)$. 


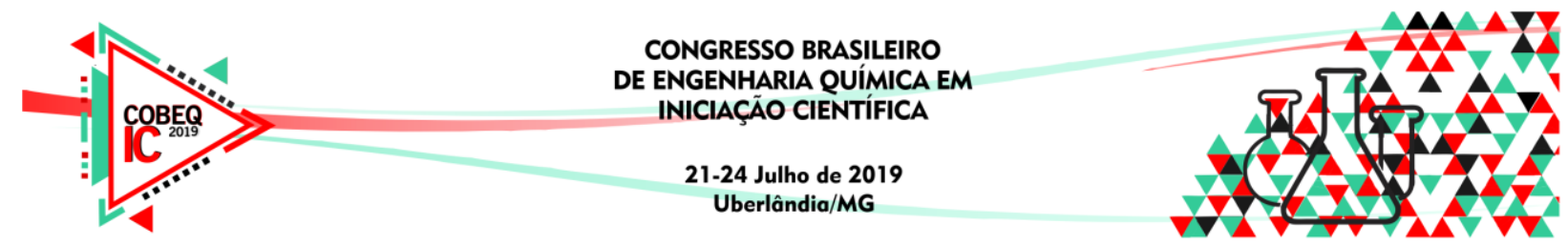

$$
X_{B S}=a \cdot e^{-b \cdot t^{n}}
$$

A taxa de secagem (W), foi estabelecida por meio da Equação 3 (GEANKOPLIS, 1993).

$$
W=\frac{-m_{S S}}{A} \frac{d X}{d t}
$$

Onde:

mss = massa do sólido seco;

$\mathrm{A}=$ área exposta a secagem.

\section{RESULTADOS E DISCUSSÃO}

\subsection{Estudo da secagem da casca do maracujá}

A curva elaborada a partir dos dados coletados durante a realização do experimento encontra-se representada pela Figura 1, onde pode-se observar que, a partir de cinco horas de secagem a umidade em base seca não varia mais. No entanto, foram necessárias quatorze horas para atingir a umidade de equilíbrio equivalente a $0,03 \%$.

Figura 1 - Curva de secagem da casca do maracujá amarelo.

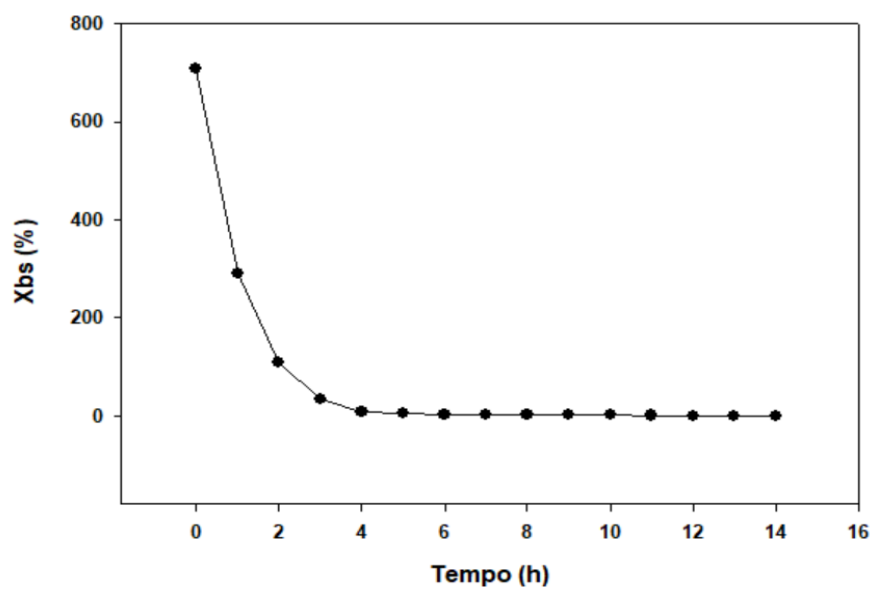

A partir da Figura 1 é possível verificar que a umidade da amostra diminui com o tempo, até o momento em que a massa da amostra se torna constante. O processo se comportou de maneira semelhante ao resultado encontrado por Ferreira e Pena (2010), que também estudaram a secagem da casca do maracujá, porém em temperaturas diferentes. 


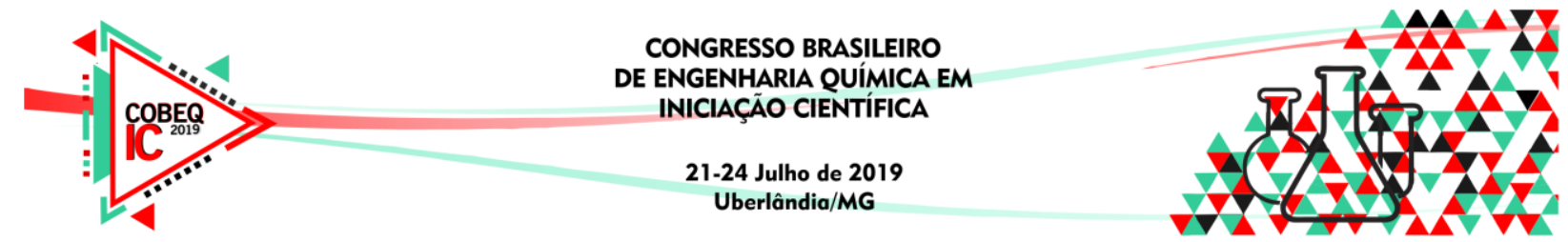

\subsection{Estudo da cinética de secagem}

Para estudo da cinética de secagem, fez-se necessário estabelecer a equação de ajuste ao modelo. A Equação foi estabelecida por meio do software SigmaPlot. Os parâmetros dos ajustes do modelo aos dados de secagem estão apresentados na Tabela 1.

Tabela 1 - Parâmetros dos ajustes matemáticos aplicados aos dados de secagem

\begin{tabular}{c|c|c|c|c}
\hline \multirow{2}{*}{ Modelo } & \multicolumn{4}{|c}{ Parâmetros do Ajuste } \\
\cline { 2 - 5 } & $\mathbf{a}$ & b & $\mathbf{n}$ & $\mathbf{R}^{2}$ \\
\hline$X_{B S}=a \cdot e^{-b \cdot t^{n}}$ & 707,6732 & 0,0098 & 1,1004 & 0,9999 \\
\hline
\end{tabular}

Por meio da Tabela 1 pode-se observar que o coeficiente de determinação $\left(\mathrm{R}^{2}\right)$ apresentou bom ajuste. A curva de taxa de secagem em função do tempo está apresentada pela Figura 2.

Figura 2 - Curva da taxa de secagem versus umidade.

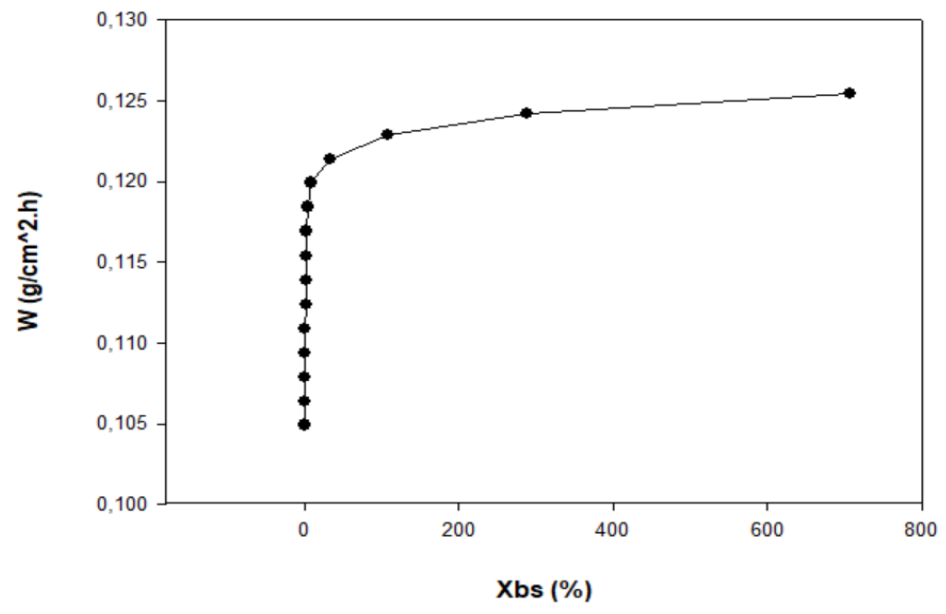

Por meio da Figura 2, percebe-se que a taxa de secagem diminui de acordo com a redução da umidade, isso porque nas primeiras horas de secagem têm-se uma maior proporção de umidade e uma maior velocidade de secagem; com o passar do tempo, a umidade tende a permanecer constante enquanto a velocidade de secagem irá ser cada vez menor.

\section{CONCLUSÃO}

Mediante o presente trabalho foram obtidas curvas de secagem da casca do maracujá, sendo estas fundamentais para a previsão do tempo de secagem e projetos de unidades em grande escala. Constatou-se que a partir de cinco horas a umidade em base seca não apresenta variações significativas. 


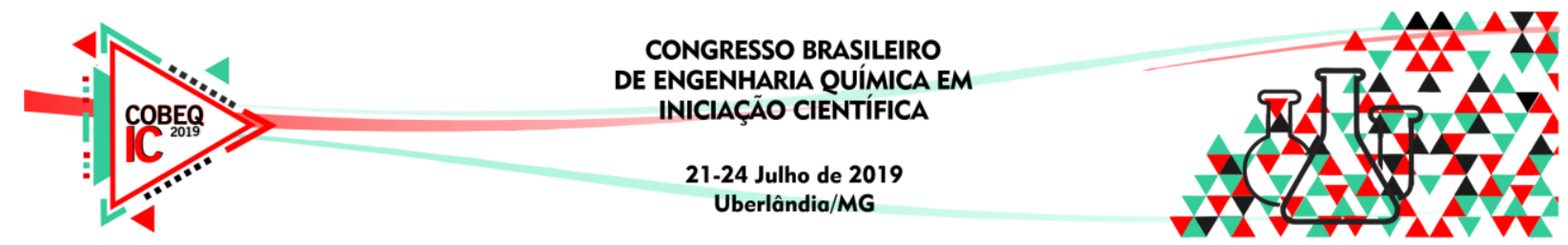

\section{REFERÊNCIAS}

AKPINAR, E. K. Mathematical modelling of thin layer drying process under open sun of some aromatic plants. Journal of Food Engineering, London, v.77, n.4, p.864-870, 2006.

COELHO, A. A.; CENCI, S. A.; RESENDE, E. D. Rendimento em suco e resíduos de maracujá em função do tamanho dos frutos em diferentes pontos de colheita para o armazenamento. Revista Brasileira de Produtos Agroindustriais, v.13, p.55-63, 2011.

FERREIRA, M. F. P.; PENA, R. S. Estudo da secagem da casca do maracujá amarelo. Revista Brasileira de Produtos Agroindustriais, Campina Grande, v. 12, n. 1, p.15$28,2010$.

FERRUA, F. Q.; BARCELOS, M. F. P. Equipamentos e embalagens utilizados em tecnologia de alimentos. Lavras: UFLA/ FAEPE, 2003.

GEANKOPLIS, C. J. Transort prosses and unit operations. 2ed. New Jersey: Prentice Hall, 1993.

MANICA, I. Fruticultura tropical: maracujá. São Paulo, Ed. Agronômica Ceres.160 p. 1981.

OLIVEIRA, L. F.; NASCIMENTO, M. R. F.; BORGES, S. V.; RIBEIRO, P. C. N.; RUBACK, V. B. Aproveitamento alternativo da casca do maracujá-amarelo (Passiflora edulis f. var. flavicarpa) para produção de doce em calda. Ciência e Tecnologia de Alimentos, Campinas-SP, v.22 (3), p. 259-262, 2002. 